\title{
Portfolio Performance Measurement: Review of Literature and Avenues of Future Research
}

\author{
Ahmed Marhfor \\ University of Quebec in Abitibi-Témiscamingue (UQAT), Rouyn-Noranda, Canada \\ Email: Ahmed.Marhfor@uqat.ca
}

Received 14 April 2015; accepted 15 April 2016; published 20 April 2016

Copyright (C) 2016 by author and Scientific Research Publishing Inc. This work is licensed under the Creative Commons Attribution International License (CC BY). http://creativecommons.org/licenses/by/4.0/ (c) (i) Open Access

\begin{abstract}
This study provides a review of the main measures of portfolio performance. We discuss their weaknesses and distinguish between traditional performance measures and more recent conditional performance measures. We show that the conditional approach addresses one major shortcoming of the traditional approach (risk stability assumption). Conditional measures allow expected returns and risk to vary with the state of the economy. We also propose new avenues for future research and some improvements to the existing measures.
\end{abstract}

\section{Keywords}

Portfolio Performance, Traditional Measures, Conditional Performance Measures, Asset Selection, Market Timing, Jensen Alpha, Conditional Alpha

\section{Introduction}

The main goal of portfolio performance evaluation is to measure value creation provided by the portfolio management industry. In recent years, the demand of "reliable and admissible" performance measures has increased as investment in mutual and exchange traded funds has exploded in popularity among small investors across the globe. This research produces a census of the main measures of portfolio performance that has been proposed in the literature. We discuss their limits and provide a classification based on their properties and objectives. It is worth mentioning that we do not cover all existing measures (a complete survey is virtually impossible) but our analysis provides an exhaustive list of the main established measures of financial performance. We distinguish between traditional (unconditional) performance measures and conditional performance measures. The traditional measures were mainly influenced by the Capital Asset Pricing Model (CAPM). Their major shortcoming 
is the assumption that risk is constant over the entire evaluation period. On the other hand, conditional measures relax this hypothesis by allowing portfolios risk and market premiums to vary over time with the state of the economy (Ferson and Schadt [1]). Recent empirical findings reveal that conditional performance techniques improve investors' perception of the portfolio management industry [2]. In this paper, we also propose some improvements to the existing approaches and identify new avenues for future research.

\section{Previous Research Work}

\subsection{Unconditional Performance Evaluation}

Our first class of performance measures includes all measures that are computed as a ratio. The most common way to calculate this category is to divide the performance (excess returns) by a risk measure.

\subsubsection{Sharpe Ratio}

A common mathematical definition of the Sharpe [2] ratio is:

$$
S_{P}=\frac{E\left(R_{P}\right)-R_{f}}{\sigma\left(R_{P}\right)}
$$

where $E\left(R_{P}\right)$ is the return of portfolio $\mathrm{P} ; R_{f}$ is the risk-free return; and $\sigma\left(R_{P}\right)$ is the standard deviation of portfolio $\mathrm{P}$ (total risk). Such ratio can be defined as the ratio of portfolio return in excess of risk-free rate over its standard deviation. Knowing that the square of the standard deviation is the variance (Markowitz [3] definition of risk), Sharpe ratio is mainly derived from Markowitz portfolio theory. It can be used for assessing the performance of a portfolio which is meant to represent an individual's total investment. In fact, Sharpe ratio is suitable for individuals who invest only in one fund. On the other hand, when an investor wants to combine multiple portfolios, the covariance between volatilities will be an issue if we rely only on Sharpe ratio. Another drawback is that Sharpe ratio does not refer to a benchmark. Furthermore, its interpretation is difficult when excess return is negative $\left(E\left(R_{P}\right)-R_{f}<0\right)$. Another problem is the assumption that portfolio returns are normally distributed.

Higher moments (e.g. third and fourth moments) are not considered by the Sharpe ratio. In the literature, many authors tried to improve the Sharpe ratio by proposing some intuitive adjustments. Within this new category of measures, we have the information ratio, the Sortino [4] ratio and Modigliani \& Modigliani [5] ratio.

\subsubsection{Information Ratio (IR)}

The IR replaces the risk-free return with the return of a benchmark portfolio. It can be written as follows:

$$
R I=\frac{E\left(R_{P}\right)-E\left(R_{B}\right)}{\sigma\left(R_{P}-R_{B}\right)}
$$

where $E\left(R_{B}\right)$ is the return of a benchmark portfolio (e.g. an index); $\sigma\left(R_{P}-R_{B}\right)$ is the tracking error (standard deviation of the difference between portfolio $P$ returns and the returns of the benchmark). In fact, the denominator of IR reflects the cost of an active management strategy. Hence, IR measures managers' ability to generate higher returns relative to a benchmark portfolio. It appraises the excepted return from an active management strategy divided by cost of such strategy. To create value for investors, managers' should maximize the expected active return (numerator) and minimize the cost of their active management style (denominator). A higher IR suggests that managers can achieve higher returns without taking on additional risk.

\subsubsection{Modigliani and Modigliani Ratio (M \& M)}

The M \& M ratio is also derived from the Sharpe ratio. It measures the returns of portfolio $\mathrm{P}$ while taking into consideration the amount of the portfolio risk relative to a benchmark. The intuition behind this measure is that a manager who has taken the same risk as its benchmark should generate returns similar to the benchmark. If the manager's portfolio gives superior returns, it means that we are witnessing a higher performance. The latter is captured by the M\&M ratio and can be considered as the incremental return added as compared to the level of market (benchmark) risk. The M\&M measure can be written as follows:

$$
R A P=\frac{\sigma_{M}}{\sigma_{P}}\left(R_{P}-R_{f}\right)+R_{f}
$$


At equilibrium, $R A P=R_{M}$ (return of the benchmark: market portfolio). When $R A P>R_{M}$, the manager generates higher performances.

\subsubsection{Sortino Ratio (SR)}

Sharpe ratio assumes that returns are normally distributed. Therefore, such ratio does not make any distinction between the upside risk and the downside risk. In reality, rational investors are only afraid of the downside risk. The SR takes into consideration the downside risk. It focuses on returns that are below a certain threshold and can be written as follows:

$$
S R_{P}=\frac{R_{P}-T H R}{\sqrt{\frac{1}{N} \sum_{t=1}^{n} D\left(R_{P, t}-T H R\right)^{2}}}
$$

where THR is a threshold return (a specified required rate of return) and $D$ is a Dummy variable set to 1 if the return of the portfolio is below THR and 0 otherwise. According to SR, only returns that fall below a specified required rate of return are taken into consideration. In fact, the Sharpe standard deviation is replaced by a new standard deviation measure which considers only returns below THR.

\subsubsection{Treynor Ratio (TR)}

The TR [6] is measured as following:

$$
T R_{P}=\frac{E\left(R_{P}\right)-R_{f}}{\beta_{P}}
$$

where $E\left(R_{P}\right)$ is the return of portfolio $\mathrm{P} ; R_{f}$ is the Risk-free return; and $\beta_{P}$ is the portfolio beta (systematic risk). The $T R$ considers the systematic risk of the portfolio instead of the total risk. One important drawback of this measure is that it requires the selection of an efficient market index. This is a very difficult task because the real market portfolio is unobservable (Roll [7]). Therefore, the sensitivity of $T R$ to the selected market index is a major concern. Finally, $T R$ is relevant for the measurement of the performance of a portfolio that does not represent the whole patrimony of an investor.

All the financial performance measures presented above do not explain the types of managers' skills that help create value for investors. In addition, they do not quantify the value added or destroyed. The second class of our traditional performance measures addresses these issues.

\subsubsection{Value at Risk (VAR) Measure}

This measure of portfolio performance answers the following question: what is the most I can lose on my investment? Therefore, this indicator is relevant for investors who are mostly concerned by extreme events. More specifically, VAR computes the potential loss in value over a time frame for a given confidence interval. For instance, if we consider a confidence level of 5\%, VAR will give the loss value in dollars that will happen such as the probability that the loss exceeds this value is $5 \%$. In other words, if a portfolio has a one-day $5 \%$ VAR equal to $\$ 10$ millions, we can say that there is $5 \%$ probability that a loss over $\$ 10$ millions will happen over a one day period if there is no trade. Sometimes, investors can also divide the value at risk by the initial value of the portfolio to obtain a percentage of the potential loss.

\subsubsection{Jensen's Alpha}

Jensen's [8] alpha measures the abnormal return in excess of what would be predicted by a broader market index. It is defined as the difference between portfolio excess return and the excess return at equilibrium. The traditional Jensen's alpha can be written as follows:

$$
R_{P t}-R_{f t}=\alpha_{P}+\beta_{P}\left(R_{M t}-R_{f t}\right)+\varepsilon_{P t}
$$

where $\alpha_{P}$ is Jensen's alpha; $\beta_{P}$ is the portfolio beta; and $\varepsilon_{P t}$ is an error term. Jensen's alpha reflects good securities picking skill of a portfolio manager. A positive and significant alpha indicates that a portfolio manager has beaten the market with his/her good assets selection skills. Like TR, Jensen's alpha is sensitive to the choice of the market index (Roll [7] critique). In reality, the market portfolio is unobservable because it should include 
every single possible available asset. Furthermore, Jensen's alpha does not allow a comparison of portfolios with different levels of risk (Cogneau and Hubner [9]). Finally, this measure does not reflect managers' market timing skills. In the literature, many adjustments have been proposed to distinguish between managers' stock picking skills and market timing skills.

\subsubsection{Treynor \& Mazuy (T \& M) Measure}

T \& M [10] measure is based on Jensen's alpha. It allows investors to distinguish between managers' stock picking skills and market timing skills. To reflect whether value creation is explained by a good market timing strategy, T\&M added a quadratic term to Jensen’s alpha measure:

$$
R_{P t}-R_{f t}=\alpha_{P}+\beta_{P}\left(R_{M t}-R_{f t}\right)+\delta_{P}\left(R_{M t}-R_{f t}\right)^{2}+\varepsilon_{P t}
$$

where $\left(R_{M t}-R_{f t}\right)^{2}$ is the quadratic term. The latter assesses managers' ability to increase (reduce) exposure to the market risk in a bull (bear) market. A positive and significant coefficient on the quadratic term indicates that managers have market timing skills because their portfolios returns are higher than market index returns in all cases (bull or bear market). The term $\left[\delta_{P}\left(R_{M t}-R_{f t}\right)^{2}\right]$ is always positive when $\delta_{P}$ is positive. In fact, when the portfolio manager is able to predict when stocks will outperform bonds (high exposure to the market) and when bonds will outperform stocks (low exposure to the market), we can say that he has a good market timing skills.

\subsubsection{Henriksson \& Merton (H \& M) Measure}

H \& M [11] proposed a different approach to determine whether value creation is due to market timing skills. More specifically, they added to the traditional Jensen's alpha a term containing a dummy variable:

$$
R_{P t}-R_{f t}=\alpha_{P}+\beta_{P}\left(R_{M t}-R_{f t}\right)+\delta_{P} D_{t}\left(R_{M t}-R_{f t}\right)+\varepsilon_{P t}
$$

where $D$ is a dummy variable set equal to 1 when the market return is above the risk-free rate and 0 otherwise. Intuitively, a positive and significant coefficient on the added term suggests that we should expect higher portfolio returns (good market timing skills) because the term $\left(\delta_{P} D_{t}\left(R_{M t}-R_{f t}\right)\right)$ is always positive when managers have high exposure to the market during a bull market period.

Empirical results of studies using traditional performance measures suggest that fund managers do not have investment ability to outperform passive investments strategies. Their management activities generate more negative alphas than positive alphas. In addition, Jagannathanand and Korajczyk [12]; and Ferson and Schadt [1] used T \& M and H \& M models to assess passive investments strategies performance. Their findings indicate that a passive investment strategy can generate positive market timing coefficients and negative stock picking coefficients (negative Jensen's alpha). Theoretically, a passive strategy should generate non significant coefficients which indicate that T \& M and H \& M models are misspecified. One potential explanation of theses puzzling findings is that risk is assumed to be constant over time by all traditional performance measures. This might seem like a very strong assumption because it is well established in the literature that investors' expectations and second moments vary over time. Another explanation is that there are other factors (e.g. Size, Book-tomarket ratio...) that may explain changes in portfolios returns. As a result, portfolios risk exposures should be allowed to vary over time in order to capture active portfolio management strategies and additional factors should be included into Jensen's traditional formula.

\subsection{Conditional Performance Evaluation and Multi-Factor Models}

Multi-factors models add new risk factors to the CAPM model. In fact, many authors argue that the single market factor is not enough to explain funds' returns. As a consequence, macroeconomic, industry and firm factors have been proposed in the literature in order to provide more reliable estimates of portfolio performance. For instance, Fama and French [13] add controls for firm size and book-to-market ratio. Carhart [14] includes a momentum effect. Other approaches rely on macroeconomic factors like interest rates and inflation. Some include indexes that are related to managers' investment style (e.g. small-growth capitalization; large-value capitalization....). 


\subsubsection{Fama-French Three-Factor Model}

This model can be written as follows:

$$
R_{P t}-R_{f t}=\alpha_{P}+\beta_{1}\left(R_{M t}-R_{f t}\right)+\beta_{2}\left(S M B_{t}\right)+\beta_{3}\left(H M L_{t}\right)+\varepsilon_{p t}
$$

where $S M B$ is the size factor (small minus big) and HML is the book-to-market factor (High minus low). These factors measure the historic excess return of small cap stocks over big cap stocks and value stocks over growth stocks.

\subsubsection{Carhart Four-Factor Model}

This model is an extension of Fama-French model. Carhart [14] includes the momentum factor. The latter is a market anomaly showing that stocks with high past performance continue to outperform stocks with low past performance. The momentum factor is proxied by a zero-cost portfolio (UMD: up minus down) that is long on past winners (stocks with strong past performance) and short on past losers (stocks with poor past performance). Carhart four-factor model can be written as follows:

$$
R_{P t}-R_{f t}=\alpha_{P}+\beta_{1}\left(R_{M t}-R_{f t}\right)+\beta_{2}\left(S M B_{t}\right)+\beta_{3}\left(H M L_{t}\right)+\beta_{4}\left(U M D_{t}\right)+\varepsilon_{P t}
$$

\subsubsection{Conditional Jensen's Alpha}

A conditional version of Jensen's alpha can be written as follows:

$$
R_{P t}-R_{f t}=\alpha_{c p}+\beta_{0 p}\left(R_{M t}-R_{f t}\right)+B_{1 p}^{\prime}\left(z_{t-1} \times\left(R_{M t}-R_{f t}\right)\right)+\varepsilon_{p t}
$$

where $\alpha_{c p}$ is the conditional alpha; $B_{1 p}^{\prime}$ is the vector measuring the sensitivity of beta to the vector of public information variable $\left(z_{t-1}\right) ; \beta_{0 p}$ is the average beta of portfolio $\mathrm{P} ; z_{t-1}$ is the difference between the realization of the macroeconomic variables (public information) and their unconditional average $\left(z_{t-1}-E(z)\right)$. The conditional measure (Equation (11)) proposed by Ferson and Schadt [1] assumes that beta is a linear function of predetermined public macroeconomic variables $\left(\mathrm{z}_{t-1}\right)$ at period $t-1$. In fact, using a Taylor series expansion, the portfolio beta can be written as follows:

$$
\beta_{p}\left(z_{t-1}\right)=\beta_{0 p}+B_{1 p}^{\prime} z_{t-1}
$$

In the literature, most studies use four predetermined macro-variables: market dividend yield, Treasury bill rate of returns, liquidity premiums and default risk premiums. A four-factor conditional model can be written as follows:

$$
\begin{aligned}
R_{P t}-R_{f t}= & \alpha_{c p}+\beta_{0 p}\left(R_{M t}-R_{f t}\right)+B_{1 p}^{\prime}\left(z_{t-1} \times\left(R_{M t}-R_{f t}\right)\right) \\
& +\beta_{2 p}\left(S M B_{t}\right)+\beta_{3 p}\left(H M L_{t}\right)+\beta_{4 p}\left(U M D_{t}\right)+\varepsilon_{p t}
\end{aligned}
$$

Conditional models allow risk exposures to vary over time based on lagged public information variables. The intuition behind such models is that managers use lagged public information (e.g. an increase in market dividend yield) to change their risk exposure. For instance, an increase in market dividend yield at $t-1$ may be a good reason for portfolio managers to increase their exposure to the market in the future. This may be possible with a portfolio beta above 1 so that future returns will be much higher if indeed we have a bull market. The opposite is also true. Ferson and Schadt [1] approach takes into consideration such possibilities. In fact, the underlying intuition behind the additional term $B_{1 p}^{\prime}\left(z_{t-1} \times\left(R_{M t}-R_{f t}\right)\right)$ is to remove from $\alpha_{c p}$ (conditional alpha) the effect of any investment strategy that can be replicated using public information. In some studies (e.g. Christopherson et al. [15]), even the alpha follows a conditional process as in Equation (12).

\subsubsection{Conditional GARCH Volatility and Performance Evaluation}

Some papers extend the literature on conditional performance by using Autoregressive Conditional Heteroskedasticity (ARCH) and Generalized Autoregressive Conditional Heteroskedasticity (GARCH) type models to measure changes overtime in the variance/covariance matrices. They propose Jensen's alpha based on a daily/monthly GARCH parameterization. The latter takes into consideration higher moments (third and fourth moments). According to Coggins et al. [16], risk under a bivariate GARCH framework is a function of all public 
information (macro and microeconomic). On the other hand, under Ferson and Schadt's [1] framework, risk is only a function of one-period lag public information (Coggins et al. [16]).

\section{Avenues of Future Research}

\subsection{T \& M Measure Revisited}

The classical model for market timing uses the convexity in the relation between portfolios returns and market returns to indicate managers' market timing ability. A successful market timing strategy implies higher betas when the market subsequently goes up and lowers betas when it goes down. However, the term $\left(R_{M t}-R_{\mathrm{ft}}\right)^{2}$ is not the return of a market timing mimicking portfolio ("hedge portfolio"). For instance, the construction of size and book-to-market factors is based on quartiles of firms' size and book-to-market ratios. SMB in Equation (9) is the average return of the three small portfolios minus the average return of the three big portfolios. In this paper, we propose a new approach by constructing a "hedge market timing portfolio". In a bull market period, our hedge portfolio will be a zero-cost portfolio that is long on financial assets with returns above the market return and short on financial assets with returns below the market return. In the same line of reasoning, during a bear market period, the market timing factor will be proxied by a zero-cost portfolio that is long on financial assets that outperform the market index and short on group of securities that underperform the market index. More specifically, we will have two "hedge market timing portfolios" based on the market being bullish or bearish. We then propose the following model:

$$
R_{P t}-R_{f t}=\alpha_{P}+\beta_{1}\left(R_{M t}-R_{f t}\right)+\beta_{2} D_{1}\left(A M B_{t}\right)+\beta_{3} D_{2}\left(A M B_{t}\right)+\varepsilon_{P t}
$$

where $D_{1}$ is a dummy variable equal to 1 during a bull market and 0 otherwise; $D_{2}$ is a dummy variable equal to 1 during a bear market and 0 otherwise; $A M B$ is the market timing factor (Above market returns minus Below market returns). A positive and significant $\beta_{2}$ and $\beta_{3}$ indicate that managers have market timing skills.

\subsection{H \& M Measure Revisited}

Based on the traditional H\&M model, the manager's portfolio beta has two values (a value above or equal to 1 when $\left(R_{M t}-R_{f t}\right)$ is positive and 0 otherwise). On the other hand, when we rely on $\mathrm{H} \& \mathrm{M}$ measure, we do not consider any relevant information linked to the duration of the bull or bear market. We also neglect information linked to the magnitude of the bull and bear market. In addition, modeling can be work out with dummies (see Equation (8) for more details) if the timing of the regime switch is known which seems a very strong assumption. Therefore, H\&M model does not reflect important elements that can alter managers' risk positions. For instance, if a manager expects a long ( 3 to 5 years) and strong bull market, his exposure to the market risk will be different form a situation where the bull market has a lower magnitude and is expected to last days or weeks. To better reflect managers' expectations about the future state of the economy, we can use regime switching models like smooth transition autoregressive (STAR) models or Threshold autoregressive (TAR) models. These models can be applied to time series data with a regime switching behavior (e.g. market index data). Based on a regime switching model, the expected duration the system is going to stay in a state of the economy can be calculated from the transition probability. Furthermore, these models allow for a higher degree of flexibility in model parameters through a regime switching behaviour (e.g. a transition from a bear market to a bull market). This flexibility is not reflected in H\&M approach. Therefore we can propose the following equation:

$$
R_{P t}-R_{f t}=\alpha_{P}+\beta_{P}\left(R_{M t}-R_{f t}\right)+\delta_{P} F+\varepsilon_{P t}
$$

$F$ should for instance play the role of a smooth transition continuous function bounded between 0 and 1 . The switch from one regime to another (e.g. from bear to bull market) depends on the past values of a market index time series data. A positive and significant $\delta_{P}$ suggests that portfolio managers are able to predict and understand when the market enters a different regime.

\subsection{Ferson \& Schadt Measure Revisited}

Instead of using lagged public information, we can rely on financial analysts' forecasts/expectations at $t-1$ and interact these forecasts with $\left(R_{M t}-R_{f t}\right)$. Hence, we propose the following equation: 


$$
R_{P t}-R_{f t}=\alpha_{c p}+\beta_{0 p}\left(R_{M t}-R_{f t}\right)+B_{1 p}^{\prime}\left(E_{t-1} \times\left(R_{M t}-R_{f t}\right)\right)+\varepsilon_{p t}
$$

where $E_{t-1}$ represents analysts' consensus forecast.

\section{Conclusion}

This research revisits and extends the main measures of portfolio performance. We show that early traditional performance measures do not control for risk-time variations associated with the state of economy and do not consider multiple risk factors. The early portfolio empirical results in the finance literature suggest that the average performance net of expenses is negative. On the other hand, when we control for risk-time variations and include additional risk factors, the average performance of funds looks better [1]. In this paper, we do not only provide an exhaustive list of portfolio performance measures, but we also propose new avenues for future research and some improvements to some existing measures.

\section{References}

[1] Ferson, W. and Schadt, R. (1996) Measuring Fund Strategy and Performance in Changing Economic Conditions. Journal of Finance, 51, 425-462. http://dx.doi.org/10.1111/j.1540-6261.1996.tb02690.x

[2] Sharpe, W.F. (1966) Mutual Fund Performance. Journal of Business, 1, 119-138. http://dx.doi.org/10.1086/294846

[3] Markowitz, H. (1952) Portfolio Selection. Journal of Finance, 7, 77-91. http://dx.doi.org/10.1111/j.1540-6261.1952.tb01525.x

[4] Sortino, F. (1994) Performance Measurement in a Downside Risk Framework. Journal of Investing, 3, 59-65. http://dx.doi.org/10.3905/joi.3.3.59

[5] Modigliani, F. and Modigliani, L. (1997) Risk-Adjusted Performance. Journal of Portfolio Management, $23,45-54$. http://dx.doi.org/10.3905/jpm.23.2.45

[6] Treynor, J. (1965) How to Rate Management of Investment Funds. Harvard Business Review, 41, 63-75.

[7] Roll, R. (1977) A Critique of the Asset Pricing Theory's Tests' Part I: On Past and Potential Testability of the Theory. Journal of Financial Economics, 4, 129-176. http://dx.doi.org/10.1016/0304-405X(77)90009-5

[8] Jensen, M.C. (1968) The Performance of Mutual Funds in the Period 1945-1964. Journal of Finance, 23, 389-416. http://dx.doi.org/10.1111/j.1540-6261.1968.tb00815.x

[9] Cogneau, P. and Hubner, G. (2009) The more than 100 Ways to Measure Portfolio Performance-Part 1: Standardized Risk-Adjusted Measures. Journal of Performance Measurement, 14, 56-69.

[10] Treynor, J. and Mazuy, K. (1966) Can Mutual Funds Outguess the Market? Harvard Business Review, 44, $131-136$.

[11] Henriksson, R.D. and Merton, R.C. (1981) On the Market Timing and Investment Performance II: Statistical Procedures for Evaluating Forecasting Skills. Journal of Business, 54, 513-534. http://dx.doi.org/10.1086/296144

[12] Jagannathan, R. and Korajczyk, R. (1986) Assessing the Market Timing Performance of Managed Portfolios. Journal of Business, 59, 217-236. http://dx.doi.org/10.1086/296326

[13] Fama, E.F. and French, K.R. (1992) The Cross-Section of Expected Stock Returns. Journal of Finance, 47, 427-465. http://dx.doi.org/10.1111/j.1540-6261.1992.tb04398.x

[14] Carhart, R.S. (1970) On the Persistence in Mutual Fund Performance. Journal of Finance, 52, 57-82. http://dx.doi.org/10.1111/j.1540-6261.1997.tb03808.x

[15] Christopherson, J.A., Ferson, W. and Glassman, D.A. (1998) Conditioning Manager Alpha on Economic Information: Another Look at the Persistence of Performance. Journal of Portfolio Management, 5, 4-12. http://dx.doi.org/10.1093/rfs/11.1.111

[16] Coggins, F., Beaulieu, M.C. and Gendron, M. (2009) Mutual Fund Daily Conditional Performance Evaluation. Journal of Financial Research, 32, 95-122. http://dx.doi.org/10.1111/j.1475-6803.2009.01244.x 